\title{
A Peculiar and Perpetual Tendency: An Asymmetry in Knowledge Attributions for Affirmations and Negations*
}

\author{
John Turri \\ john.turri@gmail.com
}

\begin{abstract}
From antiquity through the twentieth century, philosophers have hypothesized that, intuitively, it is harder to know negations (i.e. claims about what is not) than to know affirmations (i.e. claims about what $i s$ ). This paper provides direct evidence for that hypothesis. In a series of studies $(\mathrm{N}=1132)$, I found that people naturally view negations as harder to know than affirmations. Participants read simple scenarios and made judgments about truth, probability, belief, and knowledge. Participants were more likely to attribute knowledge of an outcome when framed affirmatively than when framed negatively. Participants did this even though the affirmative and negative framings were logically equivalent. The asymmetry was unique to knowledge attributions: it did not occur when participants rated truth, probability, or belief. These findings show new consequences of negation on people's judgments and reasoning and can inform philosophical theorizing about the ordinary concept of knowledge.
\end{abstract}

Keywords: knowledge attribution; negation; theory of mind

\section{Introduction}

In considering medical conditions, the weather, criminal liability, the contents of foods, and countless other topics, people often make affirmative and negative judgments — judgments of

\footnotetext{
* This is the penultimate version of a paper to appear in Erkenntnis. Please cite the final, published version if possible.
} 
what is and what is not. We judge that it will be sunny tomorrow or that it will not, that a coworker has a cold or that she does not, that the butler is guilty or that he is not. These judgments are often based on good but imperfect information. The available evidence suggests that it will rain tomorrow, but perhaps it will not. Likewise we might have good evidence that a lottery ticket will not win, but perhaps it will win anyway.

Although the likelihood of an outcome can sometimes be precisely quantified, people might have differing expectations about affirmative and negative outcomes. For instance, people might assume that affirmative outcomes can be discovered or predicted more easily than negative ones. This expectation is captured in the common saying, "You can't prove a negative," and might contribute to people's reluctance to attribute knowledge to themselves and others regarding the non-occurrence of extremely unlikely events, such as winning the lottery, or the non-existence of unlikely entities, such as ghosts (Hales, 2005).

The expectation might also be reflected in historically influential philosophical discussions of scientific method, logic, and epistemology. For example, classical Indian philosophers distinguished between positive facts (presence) and negative facts (absence) and they lengthily debated the metaphysics and epistemology of absence (abhāva) — what are absences and how, if at all, can we know that something is absent (Sharma 1966: 291)? Some argued that we know absence by perception; others argued that we know it by inference; others were dissatisfied with both positions and posited a special faculty of non-apprehension (anupalabdhi) by which absence is known (Bhatt 1989: ch. 10) Francis Bacon (1620/1960) noted a "peculiar and perpetual" tendency of "the human intellect to be more moved and excited by affirmatives than by nega- 
tives." Bertrand Russell (1919) claimed that humans are less willing to admit "negative facts" than "positive" ones. More recently, researchers have found evidence that suspicion of negative facts could be partly responsible for the appeal of classical skeptical arguments (Turri 2015a; Turri 2015b).

A tendency to view negative outcomes as more difficult to know could be of more general interest to philosophers because of the role that ordinary judgments play in philosophical theorizing. Philosophers often, though not always, appeal to patterns in commonsense judgment in order to guide theorizing about important categories. This approach is common throughout the history of philosophy. Aristotle, for instance, defended this approach when he wrote that one way to gather evidence in philosophy was to find a balance between different views about a philosophical topic "in the light not only of our conclusion and our premises, but also of what is commonly said about it" (Aristotle 350 BCE/1941, 1098b, 9-11). Thomas Reid wrote, "Philosophy has no other root but the principles of Common Sense," and that "severed from this root, its honours wither, its sap is dried up, it dies and rots" (Reid 1764/1997, p. 19). The approach remained popular in the twentieth century. For example, J.L. Austin advised that "ordinary language" should get "the first word" in philosophical theorizing (Austin 1956, p. 11). Wilfrid Sellars argued that identifying the defining features of ordinary thought — "the manifest image" — is "a task of the first importance" for philosophers (Sellars 1963, ch. 1). More recently, influential philosophers have claimed that "when common sense delivers a firm and uncontroversial answer about a nottoo-far-fetched case, theory had better agree" (Lewis 1986, p. 194)," and that firm commonsense judgments constitute "data" or "uncontroversial" starting points for philosophical theorizing 
(Hawthorne 2004, p. 8).

A tendency to view negative outcomes as more difficult to know could also have important implications for people's thought and behavior. It could affect how people draw conclusions from evidence, seek or communicate information, or attribute knowledge.

Considerable research has investigated how people make judgments about knowledge. Some researchers have studied the criteria guiding knowledge attributions in adults and children using tasks where participants have detailed information about an agent's evidence or circumstances, such as information about the evidence available to the agent, or whether the evidence is accurate (Birch \& Bloom, 2003; Pratt \& Bryant, 1990; Sodian, 1988; Sodian \& Wimmer, 1987; Starmans \& Friedman, 2012; Turri, Buckwalter \& Blouw, 2014; Turri \& Friedman, 2014; Wimmer, Hogrefe \& Perner, 1988; Woolley \& Wellman, 1993). In contrast, other studies have investigated general expectations about what others know, without providing detailed information about any agent's evidence or circumstances (e.g. Brennan \& Williams, 1995; Cimpian \& Scott, 2012; Fussell \& Krauss, 1991, 1992; Lau, Chiu \& Hong, 2001; Nickerson, Baddeley \& Freeman, 1987; Thomas \& Jacoby, 2013).

The present research combines these approaches: when told that an agent has particular evidence for a certain conclusion, knowledge attributions might vary depending on whether the conclusion is an affirmation or negation, thus revealing different expectations for the two types of conclusion.

We might predict such a tendency given previous findings on how people process affirmative and negative assertions. Many studies show that affirmations are typically processed more 
easily and quickly than negations (for reviews, see Kaup, Zwaan, \& Lüdtke, 2007 and Khelmani, Orenes, \& Johnson-Laird, 2012). For example, when asked to verify the truth of a sentence e.g. about whether a given number is odd or even, or whether a certain element is in a picture participants perform better for affirmative sentences than negative ones (e.g. Wason, 1961; Clark $\&$ Chase, 1972). If people have relative difficulty verifying the truth of negative assertions in simple tasks, this might affect their judgments about negative facts. For example, they might expect negative facts to be more difficult to know.

Relevant findings also come from studies on legal decision-making, which suggest that people are more swayed by positive evidence (Arkes, Shoots-Reinhard, \& Mayes, 2012; Eerland, Post, Rassin, Bouwmeester, \& Zwaan, 2012; Robinson \& Hastie, 1985). For example, in one study people made liability judgments about a fictional legal case where a dog was run over by a bus belonging to either of two bus companies (Arkes et al., 2012; also see Wells, 1992). Participants were more likely to hold the Blue Bus Company liable when given positive evidence that a Blue bus did hit the dog than when given negative evidence that the other bus company's bus did not hit the dog. This occurred even though both forms of evidence were probabilistically identical. This shows that people are less persuaded by negative evidence, but it does not directly address whether people view negative outcomes as more difficult to know.

The present research investigates whether people view negative outcomes as more difficult to know. Participants read a short text and made knowledge attributions. To ensure the tightest possible affirmation/negation manipulation, the affirmative and negative "outcomes" were actually the very same outcome described differently. For example, participants were asked whether 
an agent knows that a bank is either "still open" (affirmation) or "not closed" (negation), or whether an agent knows that a previously observed animal is "still there" (affirmation) or "not gone" (negation). Participants were significantly more likely to attribute knowledge when the outcome was described affirmatively than when it was described negatively. To determine whether this asymmetry could be due to other judgments that inform knowledge attributions, I also had participants rate attributions of belief, truth, and probability. I found no evidence that the affirmation/negation manipulation affected these other judgments. Overall the results show that knowledge judgments can be distinctively sensitive to the difference between affirmation and negation.

\section{Experiment 1}

This experiment tested whether participants were more likely to attribute knowledge for affirmative rather than negative outcomes. To ensure that findings were not due to peculiarities of a particular subject matter, I tested two different scenarios.

\section{Method}

\section{Participants}

One hundred sixty-four participants (61 female, aged $18-65$, mean age $=31$ years, $95 \%$ reporting native competence in English) were recruited and tested using an online platform (Amazon Mechanical Turk and Qualtrics) and were paid $\$ 0.35$ for 1-2 minutes of time. Participation was re- 
stricted to United States residents. The same basic recruitment procedures were used in all experiments reported here. Repeat participation was prevented (by AMT Worker ID) within and across experiments.

\section{Materials and Procedure}

Participants were assigned to one of four conditions in a 2 (story: menu, bank) $\times 2$ (content: affirmation, negation) between-subjects design. The content factor manipulated whether participants judged whether an agent knows an affirmation or a negation; the story factor was included as a robustness check, to ensure that any findings were not due to peculiarities of any one narrative context. Each participant read a simple scenario and rated their agreement with a single test statement attributing knowledge to the agent. Here are the scenarios and test statements, with the content manipulation in brackets:

(Menu) Jody and Kent haven't been to their favorite restaurant in two weeks, so they decide they'll eat dinner there tonight. Kent says "I can't wait to get there. I want to order what I had last time." Jody says, "You can. Their menu [is the same/has not changed]."

Jody knows that the restaurant's menu [is the same/has not changed].

(Bank) Jody and Kent leave their house to pick up some paperwork from their bank. It is $6 \mathrm{pm}$ and the bank usually closes at $7 \mathrm{pm}$. Jody says "We need to get that paperwork today." As they pull out of their driveway, Kent says, "We will. The bank is [still 
open/not closed]."

Kent knows that the bank is [still open/not closed].

Responses were collected on a standard seven-point Likert scale anchored with "strongly disagree" $(=1)$ to "strongly agree" $(=7)$, left-to-right on the participant's screen. After rating their agreement, participants went to a new screen and filled out a brief demographic survey.

\section{Results}

A 2 (story: menu, bank) $\times 2$ (content: affirmation, negation) analysis of variance revealed that knowledge attribution was unaffected by story, $\mathrm{F}(1,160)=1.53, \mathrm{p}=.218$, affected by content, $\mathrm{F}(1,160)=7.46, \mathrm{p}=.007, \eta_{\mathrm{p}}^{2}=.045$, and unaffected by their interaction, $\mathrm{F}(1,160)=0.65, \mathrm{p}=$. 422. The effect of content resulted because knowledge attribution was higher for affirmations (M $=6.11, \mathrm{SD}=0.10)$ than negations $(\mathrm{M}=5.61, \mathrm{SD}=0.15) .($ See Figure 1.) 


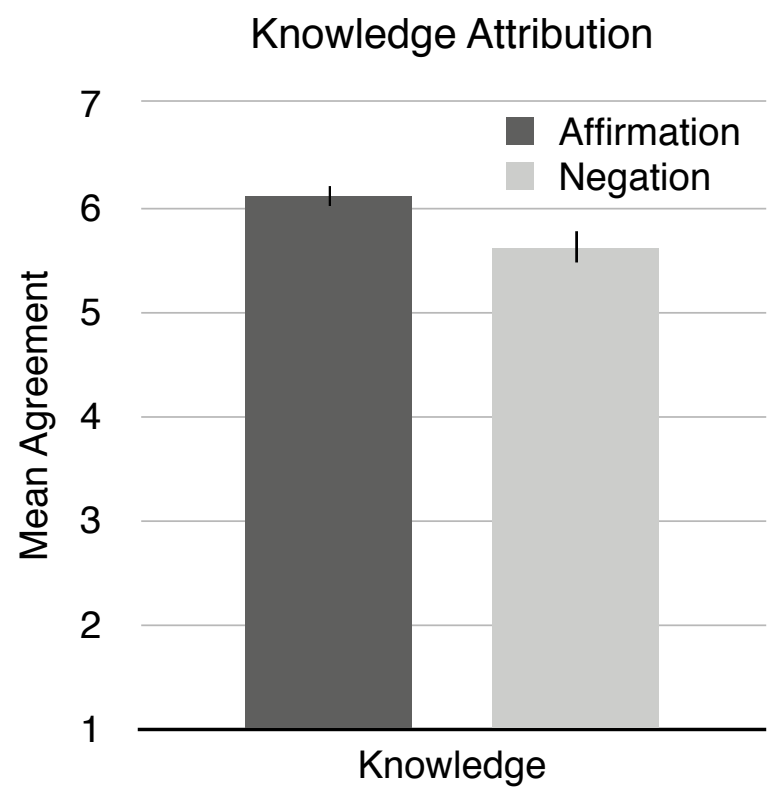

Figure 1. Experiment 1. Mean knowledge attribution for an affirmation or negation (collapsing across storyline). The scale ran 1 (strongly disagree) - 7 (strongly agree). Error bars represent +/one SEM.

\section{Discussion}

Participants were more likely to attribute knowledge of affirmative than negative outcomes. This occurred even though both outcomes corresponded to the same circumstances and differed only in how they were described. This finding supports the hypothesis that people view negative outcomes as more difficult to know. But it could have a more general explanation and not be specific to knowledge attributions. For instance, knowledge is normally viewed as requiring truth (Starmans \& Friedman, 2012; Turri, Buckwalter \& Blouw, 2014; Buckwalter, 2014). So the effect on knowledge attributions could have resulted from participants being less willing to view negations as true or probable (for related findings see Wason, 1961; Clark \& Chase, 1972). The 
next experiment investigates this possibility.

\section{Experiment 2}

This experiment again examines knowledge judgments for logically equivalent propositions that describe outcomes either positively or negatively. I expected to replicate the main finding from the first experiment. To further examine the robustness of the effect on knowledge judgments, I tested two new storylines. This time I also examined judgments of truth and probability. The principal question was whether negations would also elicit lower truth or probability judgments.

\section{Method}

\section{Participants}

Seven hundred twenty-three new participants were tested (292 female, aged 18-65 years, mean age $=32$ years, $96 \%$ reporting native competence in English).

\section{Materials and Procedure}

Participants were assigned to one of twelve conditions in a 2 (story: possum, bylaws) $\times 2$ (content: affirmation, negation) $\times 3$ (judgment: knowledge, truth, probability) between-subjects design. Each participant read a simple scenario, responded to a single test statement, and then filled out a brief demographic survey. I had no expectation for the story factor and again included it as a robustness check to ensure that any findings were not due to peculiarities of any one narrative 
context. The content factor manipulated whether participants were asked to make a judgment about an affirmation or a negation. The judgment factor manipulated which type of judgment participants were asked to make: rate the truth of a statement, the probability of the statement, or a knowledge attribution pertaining to the statement.

Here is the story used for possum and bylaw conditions, with the affirmation/negation manipulation in brackets:

(Possum) Jody and Kent see a possum sleeping in the park. Their house is at the edge of the park, so they run home to get a camera. As they are about to return to the park, Kent says, "The possum is [still there/not gone]."

(Bylaws) While Jody and Kent were out of town, their condo association voted on possible changes to the bylaws concerning pets in the neighborhood. As they return home and let out their dog, Kent says, "The bylaws [are still the same/have not changed]."

Here are the test statements for each Judgment condition. Responses were collected on standard seven-point Likert scales (qualitative anchors included below).

(Truth)

It's true that the possum is [still there/not gone].

It's true that the bylaws [are still the same/ have not changed].

"strongly disagree" $(=1)$ to "strongly agree" $(=7)$

(Probability)

How probable is it that the possum is [still there/not gone]? 
How probable is it that the bylaws [are still the same/ have not changed]

"extremely improbable" $(=1)$ to "extremely probable" $(=7)$

(Knowledge)

Kent knows that the possum is [still there/not gone].

Kent knows that the bylaws [are still the same/ have not changed].

"strongly disagree" $(=1)$ to "strongly agree" $(=7)$

\section{Results}

Figure 2 shows participants' mean responses for each story. A 2 (story: possum, bylaws) $\times 2$ (content: affirmation, negation) x 3 (judgment: knowledge, truth, probability) analysis of variance revealed that participant response was affected by story, $\mathrm{F}(1,711)=15.41, \mathrm{p}<.001, \eta_{\mathrm{p}}{ }^{2}=$. 021 , content, $\mathrm{F}(1,711)=8.36, \mathrm{p}=.004, \eta_{\mathrm{p}}^{2}=.012$, judgment, $\mathrm{F}(2,711)=80.87, \mathrm{p}<.001, \eta_{\mathrm{p}}{ }^{2}=$. 080 , and by the interaction of content and judgment, $F(2,711)=7.96, p<.001, \eta_{p^{2}}=.022$. No other interactions reached significance ( $\mathrm{ps}>.05$ ). To follow-up on the interaction between content and judgment, I separately examined whether there were effects of content for each type of judgment. These tests revealed an effect for knowledge judgments, $t(239)=4.14, \mathrm{p}<.001, \mathrm{~d}=$ 0.54. As in the first experiment, knowledge attribution was higher for affirmations ( $\mathrm{M}=4.66$, SD $=1.85)$ than negations $(\mathrm{M}=3.67, \mathrm{SD}=1.83)$. However, there was no effect of content for judgments of truth or probability, ps $>.3$. 


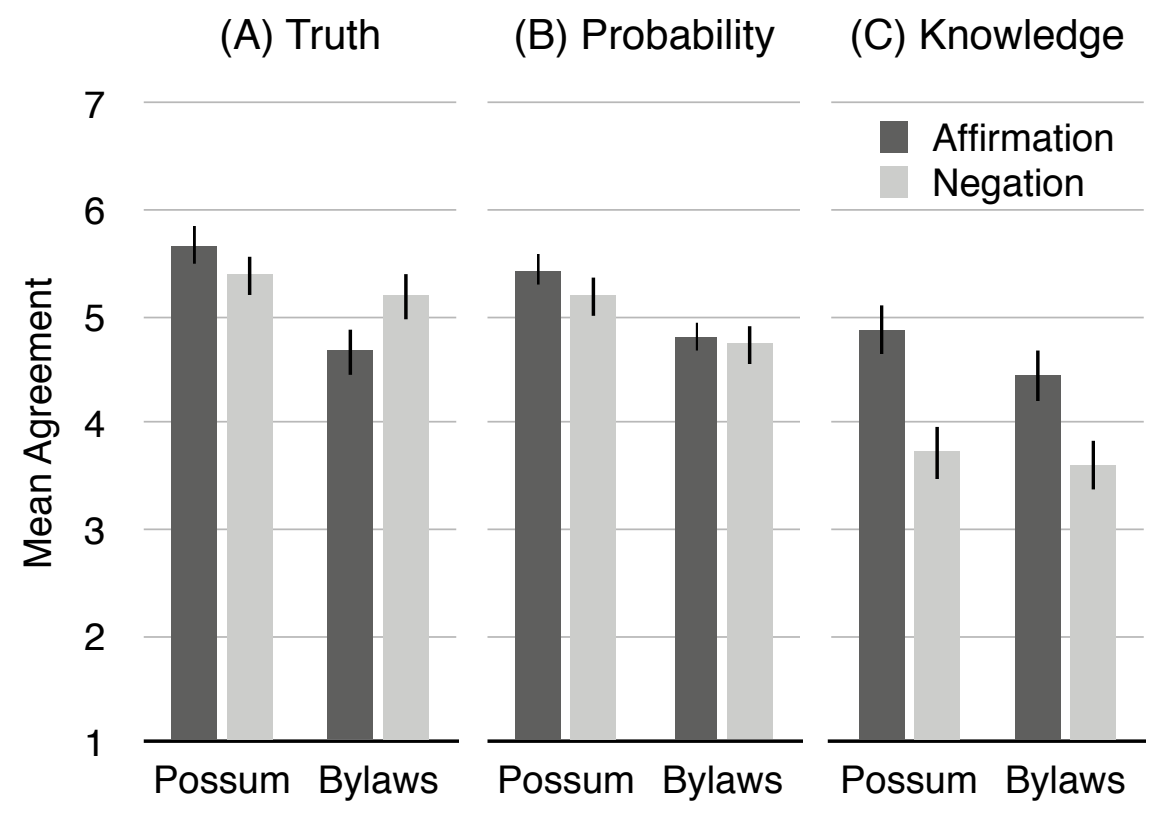

Figure 2. Experiment 2. Panel A: mean agreement with the truth probe for each story (possum/ bylaws) and in each content condition (affirmation/negation). Panel B: mean rating of the probability that the proposition was true in each content. Panel $\mathrm{C}$ : mean agreement with the knowledge attribution. Error bars represent +/- one SEM.

\section{Discussion}

Participants again recorded higher knowledge attributions for affirmations than negations, thus replicating and generalizing the principal finding of Experiment 1. The effect was specific to knowledge and did not emerge for ratings of truth or probability.

\section{Experiment 3}

This experiment again examines knowledge judgments for logically equivalent affirmations and negations. I expected to replicate the principal finding from Experiments 1 and 2. I also examined belief attributions in order to explore whether the finding on knowledge attributions might 
be due to a more general effect on theory-of-mind judgments. The principal question was whether belief attribution would be significantly lower for negations.

\section{Method}

\section{Participants}

Two hundred forty-five new participants were tested (112 female, aged 18-71 years, mean age $=$ 34 years, 98\% reporting native competence in English).

\section{Materials and Procedure}

Participants were assigned to one of four conditions in a 2 (state: think, know) $\times 2$ (content: affirmation, negation) between-subjects design. In each condition, participants read a simple story, responded to a single test statement, and then filled out a brief demographic survey. I used the possum story from Experiment 2. The State factor manipulated whether participants rated a belief attribution or a knowledge attribution. The Content factor manipulated whether the agent's mental state concerned an affirmation or a negation. Thus the conditions were distinguished by the test statement participants rated:

Kent [thinks/know] that the possum is [still there/not gone].

Responses were collected on a standard 7-point Likert scale, 1 "strongly disagree" - 7 "strongly agree." 


\section{Results}

Figure 3 shows participants' mean responses for each story. A 2 (state: think, know) $\times 2$ (content: affirmation, negation) analysis of variance revealed that participant response was affected by state, $\mathrm{F}(1,1,241), \mathrm{p}<.001, \eta_{\mathrm{p}}{ }^{2}=.283$, and affected by content, $\mathrm{F}(1,241), \mathrm{p}=.030, \eta_{\mathrm{p}}{ }^{2}=.019$, but not by their interaction, $p=.163$. I examined whether there was an effect of content for each state separately. These tests revealed no effect of content on belief attribution, $t(119)=1.29, \mathrm{p}=$. 201, but it revealed a trending effect in the predicted direction on knowledge attribution, $t(122)=$ $1.90, \mathrm{p}=.06, \mathrm{~d}=0.34$. (A one-tailed test would be appropriate here because the prediction was directional and based on the findings in the first two experiments, in which case the p-value would fall below the conventional threshold of statistical significance, $p<.05$.) As in the first two experiments, knowledge attribution was higher for affirmations $(\mathrm{M}=4.80, \mathrm{SD}=2.13)$ than negations $(\mathrm{M}=4.08, \mathrm{SD}=2.11)$. 


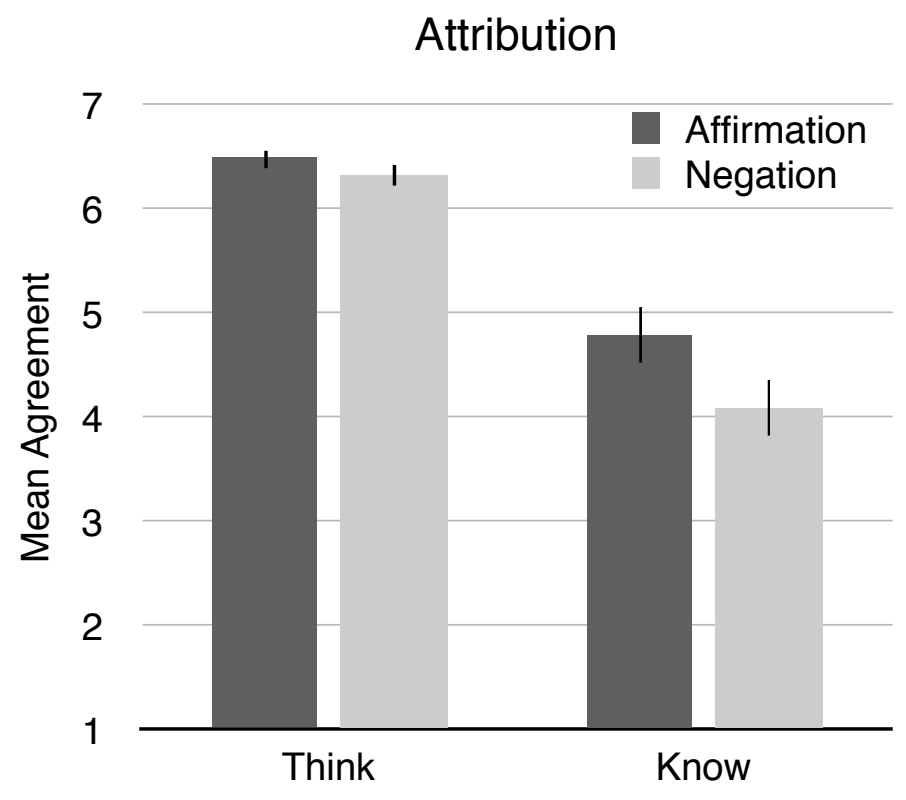

Figure 3. Experiment 3. Mean agreement that the agent "thinks" or "knows" an affirmation or a negation. Error bars represent +/- one SEM.

\section{Discussion}

Participants again recorded higher knowledge attributions for affirmations than negations, again replicating a principal finding from Experiments 1 and 2. This effect was specific to knowledge and did not emerge for belief attributions.

\section{Conclusion}

"You can't prove a negative," it is often said, and in philosophical discussions of scientific methodology and logic, it has long been suspected that humans are more suspicious of "negatives" than "affirmatives" (Bacon, 1620/1960; Russell, 1919). The present findings reveal that 
people treat negations as more difficult to know than affirmations. People were less willing to attribute knowledge of a negative statement than of an affirmative statement. Strikingly, this asymmetry occurred when comparing logically equivalent negations and affirmations.

A reasonable initial hypothesis is that the effect on knowledge attributions is due to processing fluency. Prior research shows that the extent to which information is processed fluently (i.e. with subjective ease) can affect judgments of truth. More specifically, increasing processing fluency typically increases the likelihood that statements will be judged true or accurate (e.g. Begg, Anas, \& Farinacci, 1992; McGlone \& Tofighbakhsh, 2000; Reber \& Schwarz, 1999; Alter \& Oppenheimer, 2009). And, on the ordinary understanding, truth is relevant to knowledge (Starmans \& Friedman, 2012; Turri, Buckwalter \& Blouw, 2014; Buckwalter, 2014). So it might be argued that the effect on knowledge attributions is due to diminished fluency via an underlying truth judgment regarding negations. The results of Experiment 2 are relevant to evaluating this hypothesis. In particular, it is undermined by the fact that the affirmation/negation manipulation did not affect truth or probability judgments (Experiment 2). However, it is still a theoretical possibility that the difference between affirmation and negation would affect truth judgments if they were collected in the same context as knowledge judgments. Future research could explore this more complicated possibility by including both judgments within-subjects.

A second hypothesis is that the finding on knowledge attributions is due to a more general effect on theory-of-mind judgments. Attributions of mental states, such as knowledge or belief, often involve perspective-taking: one considers how things seem from another's perspective. Yet first-order judgments of truth or probability need not involve perspective-taking: one need only 
consider the question from one's own perspective. Perhaps, then, the increased cognitive load associated with perspective-taking facilitates the negation/affirmation effect on knowledge judgments. The results of Experiment 3 are relevant to evaluating this hypothesis. In particular, it is undermined by the fact that the negation/affirmation manipulation did not affect belief attributions (Experiment 3). However, it is still a theoretical possibility that belief attributions are unusual among theory-of-mind judgments in being unaffected by this factor. Future research could explore this by testing other theory-of-mind judgments, such as the attribution of wants or intentions.

A third hypothesis is that people hold a lay theory that negative facts are difficult to detect and apply it to negative knowledge attributions even when they refer to outcomes that can be expressed affirmatively. Expectations that negative facts are more difficult to detect than positive facts might result from everyday experiences. For example, confirming absence might often require exhaustive search whereas confirming presence does not. Although it may take a long time to discover that there is a needle in a haystack, it will take even longer to show that none is there.

One might object to this hypothesis on the grounds that there is no general tendency for exhaustive search to be associated more with negations than affirmations. For example, consistent with the proposed hypothesis, verifying the sentence "Joshua has eaten meat" requires only a single observation, but verifying the sentence "Joshua has not eaten meat" would presumably involve many more observations. By contrast, and contrary to the proposed hypothesis, consider the sentences "Joshua has been faithful to his vows" and "Joshua has not been faithful to his vows." Regarding this pair, one might claim that the affirmation actually requires a more exhaus- 
tive search.

In response, the objection could very well be correct and it would be counterproductive to suggest otherwise. Whether people tend to associate negations with more exhaustive search requirements is an open empirical question. Only further research designed specifically to address it will advance the discussion beyond the speculative hypotheses offered here. In that spirit, it could be worth noting that my intuitive reaction to "There is no needle in the haystack" (the example used to motivate the hypothesis) is very different from "Joshua has been faithful to his vows" (the example used to motivate the objection). Verifying "There is no needle in the haystack" would presumably involve searching through the entire stack, whereas verifying "There is a needle in the haystack" could be verified by a single observation, perhaps even the first one. By contrast, both "Joshua has been faithful to his vows" and "Joshua has not been faithful to his vows" could be verified by a single observation, or so it seems to me. If there is an occasion on which Joshua was faithful, then he has been faithful; and if there is an occasion on which Joshua was unfaithful, then he has been unfaithful. Consistent with that, it could be that although many negation/affirmation pairs don't differ in their perceived search requirements, a nontrivial number of them do, and when this happens, the negation has stricter requirements. This could be enough to create a weak, general association between negations and greater difficulty, which in turn could produce the principle finding of interest observed here.

A fourth hypothesis, broadly consistent with the third, is that the difference between "outside" and "inside" information (Lagnado \& Sloman, 2004) explains the negation/affirmation effect on knowledge attributions. Outside information is generic and pertains to a base rate within a 
population. Inside information is specific and pertains to a particular item's propensity. Prior research has shown that people's decision-making is affected by the difference between outside and inside information (Wells, 1992; Turri, Friedman \& Keefner, 2017). Importantly for present purposes, people are also less likely to attribute knowledge based on outside information than on inside information (Friedman \& Turri, 2014). For example, when an agent receives information that $99 \%$ of all lottery tickets lose (outside information), people judge that she does not know that her ticket will lose. By contrast, when an agent receives information that her specific ticket is $99 \%$ likely to lose (inside information), people judge that she knows that her ticket will lose. Despite this difference in knowledge judgments, people rate the likelihood of her ticket losing similarly in both cases (i.e. 99\%) (Turri 2019). An intriguing possibility, then, is that people tend to view information about absence as generic, effectively indicating a $0 \%$ distribution of a certain property in an area of interest, whereas they view information about presence as specific and pertaining to a particular item's propensity, effectively generating a signal that a certain fact obtains. In order to explain the present findings, we needn't hypothesize that all evidence for knowledge attributions with negations is understood as outside evidence. Instead, a tendency to view it this way would be enough. It remains for future work to test this and other possibilities.

A fifth hypothesis is worth mentioning. It could be that there is no deeper explanation for the principal finding of interest. That is, it could be a basic linguistic or psychological fact that people tend to view negations as harder to know than affirmations. From a certain perspective, this would be the least satisfying account of the phenomenon, and I consider it to be unlikely. Nevertheless, nothing in the existing evidence speaks against the hypothesis, so it remains a gen- 
uine possibility.

Regardless of the ultimate explanation, the present findings increase knowledge of how people evaluate affirmative and negative assertions. Many previous studies have examined the relative ease of processing these assertions. For example, reaction-time measures have been used to compare how quickly people confirm affirmative and negative assertions (e.g. Wason, 1961; Clark \& Chase, 1972) and to examine the accessibility of concepts mentioned in negative and affirmative texts (e.g. Kaup, 2001; Kaup \& Zwaan, 2003; see Kaup et al., 2007 for a review of this literature). A few further studies have examined the consequences of affirmative and negative evidence on people's beliefs about outcomes in legal decision-making contexts (e.g. Arkes et al., 2012; Eerland et al., 2012; Robinson \& Hastie, 1985). To my knowledge, the present research is the first to show an affirmation/negation effect on knowledge judgments specifically, when a similar effect is not observed for judgments of truth, probability, or belief.

This finding is important because knowledge judgments play an important role in normative social cognition. Even more than attributions of belief or certainty, attributions of knowledge are closely related to how we think other people should act (Turri 2015c; Turri 2016a; Turri 2016b). Thus a tendency to view negative outcomes as less detectable could have far-reaching implications for people's thought and behavior. The existence of this tendency suggests that appropriately acting based on negative conclusions requires stronger or more conclusive evidence. This tendency might likewise explain why many people are unwilling to rule out the possibility that supernatural entities such as ghosts do not exist (e.g. Losh \& Nzekwe, 2011; Shtulman, 2013). People might be biased against viewing such negative outcomes as open to detection. 
Acknowledgments - For helpful comments and feedback, I thank Angelo Turri and two reviewers for Erkenntnis. Special thanks to Ori Friedman for an extraordinary amount of generosity and insight on this project (in my view, he deserves as much credit for it as I do). This research was supported by the Social Sciences and Humanities Research Council of Canada, the Ontario Ministry of Economic Development and Innovation, and the Canada Chairs Research program.

\section{References}

Arkes, H. R., Shoots-Reinhard, B., \& Mayes, R. S. (2012). Disjunction between probability and verdict in juror decision making. Journal of Behavioral Decision Making, 25, 276-294.

Bacon, F. (1620/1960). The new organon and related writings. New York: Liberal Arts Press.

Bhatt, G. P. (1989). The basic ways of knowing: an in-depth study of Kumārila's contribution to Indian epistemology (2nd ed.). Delhi: Motilal Banarsidass.

Birch, S. A., \& Bloom, P. (2003). Children are cursed An asymmetric bias in mental-state attribution. Psychological Science, 14(3), 283-286. doi: 10.1111/1467-9280.03436

Brennan, S. E., \& Williams, M. (1995). The feeling of another' s knowing: Prosody and filled pauses as cues to listeners about the metacognitive states of speakers. Journal of Memory and Language, 34(3), 383-398. doi: 10.1006/jmla.1995.1017

Buckwalter, W. (2014). Factive verbs and protagonist projection. Episteme.

Chase, W. G., \& Clark, H. H. (1971). Semantics in the perception of verticality. British Journal of Psychology, 62, 311-326. 
Cimpian, A., \& Scott, R. M. (2012). Children expect generic knowledge to be widely shared. Cognition, 123(3), 419-433. doi: 0.1016/j.cognition.2012.02.003

Clark, H.H., \& Chase, W.G. (1972). On the process of comparing sentences against pictures. Cognitive Psychology, 3, 472-517.

Eerland, A., Post, L. S., Rassin, E., Bouwmeester, S., \& Zwaan, R. A. (2012). Out of sight, out of mind: The presence of forensic evidence counts more than its absence. Acta Psychologica, 140, 96-100.

Fussell, S. R., \& Krauss, R. M. (1991). Accuracy and bias in estimates of others' knowledge. European Journal of Social Psychology, 21(5), 445-454. doi: 10.1002/ejsp. 2420210507

Fussell, S. R., \& Krauss, R. M. (1992). Coordination of knowledge in communication: Effects of speakers' assumptions about what others know. Journal of personality and Social Psychology, 62(3), 378-391. doi: 10.1037/0022-3514.62.3.378

Hales, S. D. (2005). Thinking tools: You can prove a negative. Think, 4, 109-112.

Kaup, B. (2001). Negation and its impact on the accessibility of text information. Memory \& Cognition, 29, 960-967.

Kaup, B., \& Zwaan, R. A. (2003). Effects of negation and situational presence on the accessibility of text information. Journal of Experimental Psychology: Learning, Memory, and Cognition, 29, 439-446.

Kaup, B., Zwaan, R. A., \& Lüdtke, J. (2007). The experiential view of language comprehension: How is negation represented? In F. Schmalhofer \& C. A. Perfetti (Eds.), Higher level 
language processes in the brain: Inference and comprehension processes (pp. 255-288). Mahwah, NJ: Lawrence Erlbaum.

Khemlani, S., Orenes, I., \& Johnson-Laird, P. N. (2012b. Negation: A theory of its meaning, representation, and use. Journal of Cognitive Psychology, 24(5), 541-559. doi: $10.1080 / 20445911.2012 .660913$

Lau, I. Y. M., Chiu, C. Y., \& Hong, Y. Y. (2001). I know what you know: Assumptions about others' knowledge and their effects on message construction. Social Cognition, 19(6), 587-600. doi: 10.1521/soco.19.6.587.20888

Losh, S. C., \& Nzekwe, B. (2011). Creatures in the classroom: Preservice teacher beliefs about fantastic beasts, magic, extraterrestrials, evolution and creationism. Science \& Education, 20, 473-489.

Lagnado, D., \& Sloman, S. A. (2004). Inside and outside probability judgments. In D. J. Koehler \& N. Harvey (Eds.), Blackwell handbook of judgment \& decision making (pp. 157-176). Malden, Mass: Blackwell.

Nickerson, R. S., Baddeley, A., \& Freeman, B. (1987). Are people's estimates of what other people know influenced by what they themselves know? Acta Psychologica, 64(3), 245-259. doi: 10.1016/0001-6918(87)90010-2

Pratt, C., \& Bryant, P. (1990). Young children understand that looking leads to knowing (so long as they are looking into a single barrel). Child Development, 61(4), 973-982. doi: 10.1111/j.1467-8624.1990.tb02835.x

Robinson, L. B., \& Hastie, R. (1985). Revision of beliefs when a hypothesis is eliminated from 
consideration. Journal of Experimental Psychology: Human Perception and Performance, 11, 443-456.

Russell, B. (1919). On propositions: What they are, and how they mean. Proceedings of the Aristotelian Society, Supplementary Volumes, 2, 1-43.

Sharma, D. (1966). Epistemological negative dialectics of indian logic - "abhāva" versus "anupalabdhi". Indo-Iranian Journal, 9(3), 291-300.

Shtulman, A. (2013). Epistemic similarities between students' scientific and supernatural beliefs. Journal of Educational Psychology, 105, 199-212

Sodian, B. (1988). Children's attributions of knowledge to the listener in a referential communication task. Child Development, 59(2), 378-385. doi: 10.2307/1130317

Sodian, B., \& Wimmer, H. (1987). Children's understanding of inference as a source of knowledge. Child Development, 58(2), 424-433. doi: 10.2307/1130519

Starmans, C., \& Friedman, O. (2012). The folk conception of knowledge. Cognition, 124(3), 272-283. doi:10.1016/j.cognition.2012.05.017

Thomas, R. C., \& Jacoby, L. L. (2013). Diminishing adult egocentrism when estimating what others know. Journal of Experimental Psychology: Learning, Memory, and Cognition, 39(2), 473-486. doi: 10.1037/a0028883

Turri, J. (2015a). Skeptical appeal: the source-content bias. Cognitive Science, 39(2), 307-324. http://doi.org/10.1111/cogs.12153

Turri, J. (2015b). An open and shut case: epistemic closure in the manifest image. Philosophers' Imprint, 15(2), 1-18. 
Turri, J. (2015c). Evidence of factive norms of belief and decision. Synthese, 192(12), 40094030. http://doi.org/10.1007/s11229-015-0727-z

Turri, J. (2016a). Knowledge and the norm of assertion: an essay in philosophical science. Cambridge: Open Book Publishers.

Turri, J. (2016b). Knowledge, certainty, and assertion. Philosophical Psychology, 29(2), 293299. http://doi.org/10.1080/09515089.2015.1065314

Turri, J. (2019). Knowledge attributions and lottery cases: a review and new evidence. In I. Douven (Ed.), The lottery problem. Cambridge: Cambridge University Press.

Turri, J., Buckwalter, W., \& Blouw, P. (2014). Knowledge and luck. Psychonomic Bulletin \& Review. doi:10.3758/s13423-014-0683-5

Turri, J. \& Friedman, O. (2014). Winners and losers in the folk epistemology of lotteries. In J. Beebe (Ed.), Advances in experimental epistemology. New York: Continuum.

Turri, J., Friedman, O., \& Keefner, A. (2017). Knowledge central: a central role for knowledge attributions in social evaluations. Quarterly Journal of Experimental Psychology, 70(3), 504-515. http://doi.org/10.1080/17470218.2015.1136339

Wason, P. C. (1961). Response to affirmative and negative binary statements. British Journal of Psychology, 52, 133-142.

Wells, G. L. (1992). Naked statistical evidence of liability: Is subjective probability enough? Journal of Personality and Social Psychology, 62, 739-752.

Wimmer, H., Hogrefe, G.J., \& Perner, J. (1988). Children's understanding of informational access as source of knowledge. Child Development, 59(2), 386-396. doi: 


\section{$10.2307 / 1130318$}

Woolley, J. D., \& Wellman, H. M. (1993). Origin and truth: Young children's understanding of imaginary mental representations. Child Development, 64(1), 1-17. doi: 10.1111/j. 1467-8624.1993.tb02892.x. 